\title{
Variations in the ultrastructure of the flight muscles of the polymorphic cricket, Gryllus firmus (Orthoptera: Gryllidae)
}

\author{
Cheng-Ji JIANG*, Bao-Chang ZHANG*, Wen-Feng CHEN, Qing-Wen ZHANG, Zhang-Wu ZHAO**, Chun-Ju An \\ and JIE-PING LI
}

College of Agronomy and Biotechnology, China Agricultural University, Beijing 100193, P.R. China; e-mail: zhaozw@cau.edu.cn

Key words. Orthoptera, Gryllidae, Gryllus firmus, flight muscle, ultrastructure, juvenile hormone, Transmission Electron Microscope

\begin{abstract}
Although there is a considerable amount of information on the ecology, genetics and physiology of life-history traits there is little information on the morphological variations associated with flight ability within species. In this paper, the morphology and ultrastructure of certain organelles in the flight muscles of Gryllus firmus are recorded using transmission electron microscopy. The ultrastructure of the flight muscles of 7-day-old female adults reveals that the ratio of thick to thin filaments is $1: 3$. Each thick filament is surrounded by 6 thin filaments in a hexagonal arrangement. The length of the sarcomere of each myofibril is significantly shorter and diameter of the myofibrils significantly smaller in long-winged than in short-winged morphs. However, the thick filaments in the long-winged morph are denser than those in the short-winged morph. Furthermore, in the long winged morph there are a greater number of mitochondria than in the short-winged morph. These differences correspond with the fact that long-winged crickets are stronger fliers than short-winged crickets.
\end{abstract}

\section{INTRODUCTION}

Flight is important for insect dispersal. In the jargon of the aeronautics industry, flight pushes the envelope of organism design (Dickinson, 1997). Flight muscle is one of the most widely studied flight-related tissues in insects mainly because of the variation in the metabolic activity of the different types of muscle (Sacktor, 1970; Usherwood, 1975, Mentel et al., 2003). All muscles receive excitatory innervation from glutamatergic neurons, inhibitory innervation from GABAergic neurons and modulatory innervation from octopaminergic dorsal unpaired median (DUM) neurons (Biserova \& Pfluger, 2004). Energy for flight is provided primarily by the very high levels of glucose and lipid in the blood. Adipokinetic hormone $(\mathrm{AKH})$ is very important in the metabolism of lipids and triggers the release of octopamine from octopamine-releasing neurons, such as the DUM neurons (Birkenbeil, 1971), which in turn activates catabolic enzymes, such as lipases and phosphorylases (Fassold et al., 2010).

The main insect muscles are the leg muscles, pleuroaxillary "steering" muscles and flight muscle (Biserova \& Pfluger, 2004). There are two types of flight muscle in insects, direct and indirect. Crickets have direct flight muscles and what is called a synchronous flight muscle system. This system is characterized by closely packed flight muscles and relatively slow wing-beat frequencies. The closely packed flight muscles have the following characteristics: the peripheral muscle fibers are surrounded by a large number of mitochondria and the muscle nuclei are closely distributed in inner membrane (Ruppert et al., 2003).

Flight polymorphism (also called dispersal or wing polymorphism) occurs widely in the Insecta and involves discontinuous variation in a wide variety of traits involved in flight and reproduction (Dingle, 1996; Zera \& Denno, 1997; Zera \& Harshman, 2001). The flight muscles of the cricket Gryllus firmus are polymorphic and pink or white in colour (Zera et al., 1997). The white muscles are small and have a few small muscle fibers, and in terms of in vitro enzyme activities and respiration rates are less active than the pink muscles of fully winged adults (Zera \& Deno, 1997). Crickets usually fly at night and under laboratory conditions begin flying immediately the lights are turned off.

The ultrastructure of the flight muscles, especially those associated with insect growth and development is well described (Herold, 1965; Reedy, 1968; Davies, 1974; Mizisin \& Ready, 1986; Novicki, 1989; Reedy \& Beall, 1993; Mentel et al., 2003; Biserova \& Pfluger, 2004). The juvenile hormone $(\mathrm{JH})$ is critical for both the growth and degeneration of flight muscles (Novicki, 1989; Rose, 2004). In the cricket Acheta domestica, the dorsal longitudinal muscle increases in size during the first 2 days of adulthood and begins to degenerate on day 4 when the level of JH increases (Chudakova \& Bocharova-Messner, 1968; Srihari et al., 1975). Overall, low levels of JH are required for muscle growth and high levels cause the flight muscle to degenerate. However, there is one notable exception, during adulthood, the $\mathrm{JH}$ titer in the haemolymph undergoes a daily cycle with a high titer

\footnotetext{
* These authors contributed equally to this work.

** Corresponding author.
} 

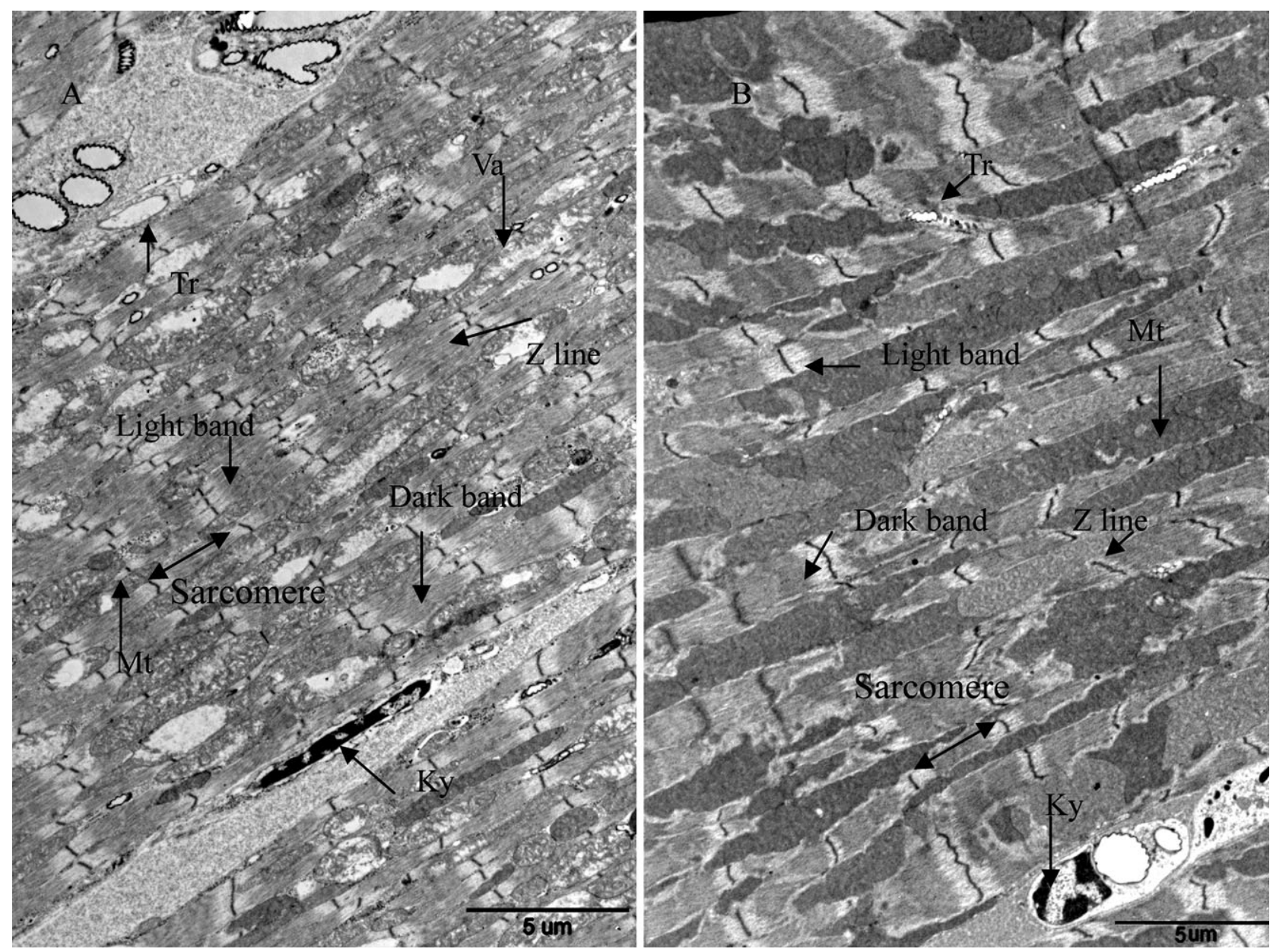

Fig. 1. Basic structure of the flight muscles. A - a longitudinal section of the flight muscle of a LW cricket $(\times 6000)$; B - a $1 \mathrm{SW}$ cricket $(\times 6000)$. $\mathrm{Tr}$ - trachea; $\mathrm{Mt}$ - mitochondrion; Ky - nucleus; $\mathrm{Mf}-$ myofibril; $\mathrm{Sr}$ - endoplasmic reticulum; Va - vacuole. The $\mathrm{Z}$ band is black and the $\mathrm{Z}$ lines are the two black lines. There are both light and dark bands in a sarcomere.

about $4 \mathrm{~h}$ before lights off, which is maintained for only a short period (Zhao \& Zera, 2004b).

It is unknown whether this short spike in JH concentration affects flight-muscle tissue and in order to determine whether this is the case transmission electron microscopy (TEM) was used to record the ultrastructure of adult flight muscles before and after flight.

\section{MATERIAL AND METHODS}

\section{Insects, morph designations and rearing conditions}

There are two morphs of Gryllus firmus (Orthoptera: Gryllidae), the sand cricket, which lives in the southeastern United States, a long-winged (LW) morph, some of which are capable of flight and a short-winged (SW) morph that is obligatorily flightless (Veazy et al., 1976). All SW females have white, nonfunctional flight muscles that never fully develop. All LW females initially have large, pink flight muscles at the adult moult and are denoted as LW(f). After about 5-6 days some LW(f) individuals begin to histolyze their flight muscles and become flightless (denoted LW(h); see Zera et al., 1997). Only the ultrastructure of the flight muscles of $\mathrm{LW}(\mathrm{f})$ individuals was determined in the present study. The G. firmus used in this study came from LW- and SW-selected lines (Block-1; see Zera \& Cisper, 2001).

Crickets were reared under a $16 \mathrm{~L}: 8 \mathrm{D}$ photoperiod at $28^{\circ} \mathrm{C}$. They were fed a standard diet. The details of the rearing conditions are the same as those described in Zera \& Cisper (2001).
LW(f) crickets began flying after day 5 of adulthood and SW crickets began reproducing on day 4 . Therefore, 7 day old females were used in the comparitive study of dispersal and reproduction. Samples consisting of five crickets were separately collected at 12:00 (control), 21:00 ( $1 \mathrm{~h}$ before lights off) and 24:00 ( $2 \mathrm{~h}$ after lights off) hours. This experiment was repeated 3 times.

\section{Tissue treatment for TEM}

The flight muscles were dissected and fixed in $2.5 \%$ glutaraldehyde overnight. After fixation, the samples were rinsed 3 times in $0.1 \mathrm{M}$ PBS buffer and post-fixed in $1 \%$ osmium tetroxide. Then the specimens were again washed in the $0.1 \mathrm{M}$ PBS buffer and dehydrated separately in a series of acetone solutions, namely $30 \%, 50 \%, 70 \%, 80 \%, 90 \%$ and $100 \%$. After that, the muscles were preserved in Epon-Araldite resin overnight for embedding. Ultra-thin sections (500-1000A) obtained using a LEICAUC6 i type slicer were stained with uranyl acetate and lead citrate, and then observed and photographed using a JEM-123 OLYMPUS TEM. The myofibrillar diameter was measured using a TEM micro-ruler. Numbers and shapes of mitochondria in the two morphs were counted in an area of 100 $\mu \mathrm{m}^{2}$.

\section{Statistical analysis}

Data were statistically analyzed using Repeated-Measures ANOVA in GraphPad Prism 4.0 software. More details are presented in the figure legends. The results shown in tables and figures are expressed as means \pm standard errors. 


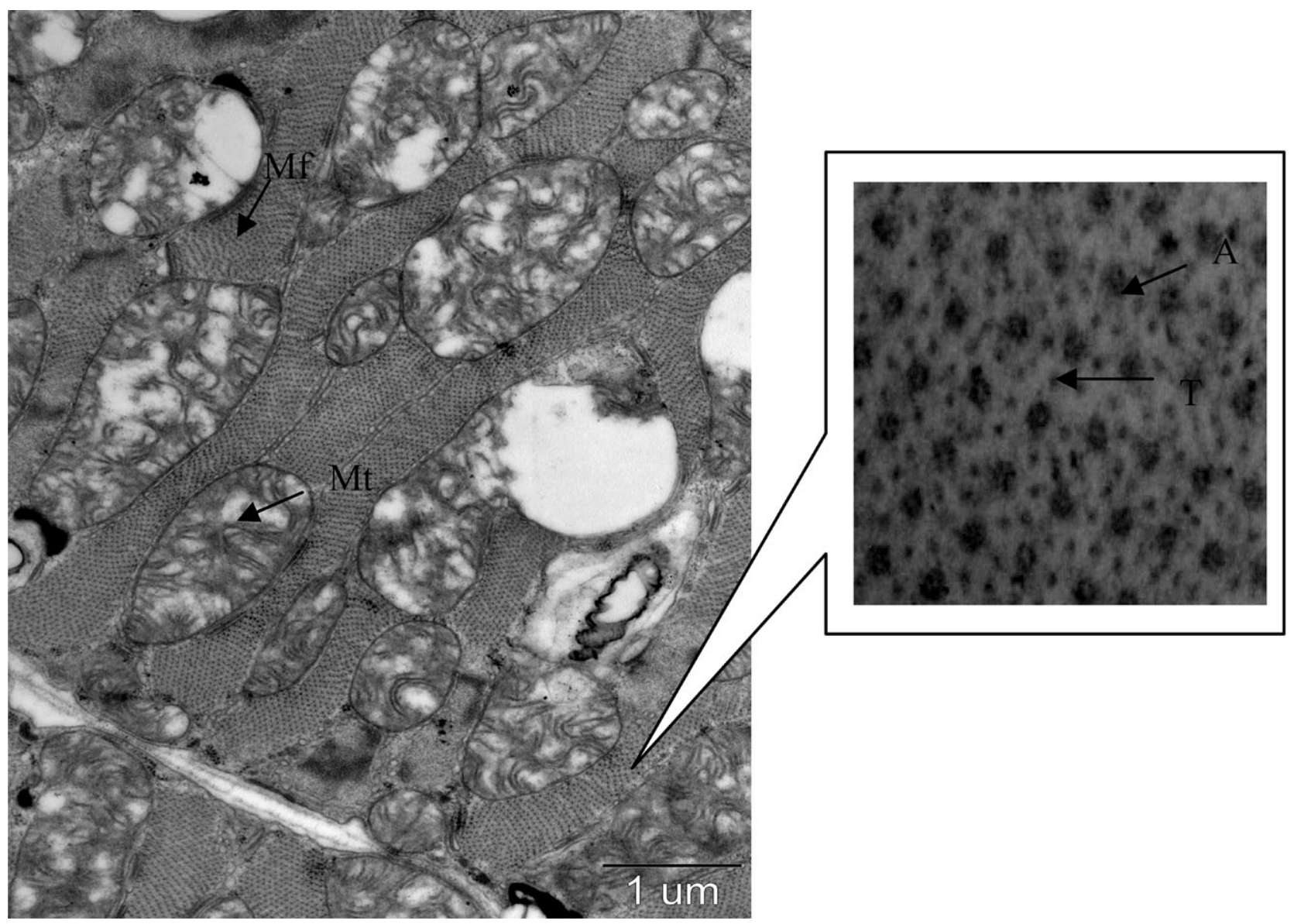

Fig. 2. Cross-section of a myofibril in the fight muscle of a sand cricket $(\times 25,000)$. Mf - myofibril; Mt - mitochondrion; $\mathrm{T}-$ thick filament; A - thin filament. The right image shows a magnified myofibril $(\times 100,000)$.

\section{RESULTS}

\section{Basic structure of flight muscles}

TEM results showed adult female sand crickets have typical structural features with synchronous flight muscles. The long- and short-winged crickets had similar subcellular structures (Figs 1A and B).

\section{Myofibrils}

Viewed in cross-section, each myofibril is surrounded by a large number of mitochondria, which are oval or polygonal in shape and separated from the sarcoplasmic reticulum (Figs $1 \mathrm{~B}$ and 2). One characteristic feature of the myofibril is the accurate arrangement of myofilaments during the development of the flight muscle. Each myosin filament (thick filament) is surrounded by six actin filaments (thin filaments) forming a hexagram, and each actin filament is located between two myosin filaments, giving a ratio of thick to thin filaments of $1: 3$. In longitudinal section a muscle fiber is cylindrical in shape with sarcomeres of around 2.0-4.1 $\mu \mathrm{m}$ in length (Figs 2 and 3).

\section{Differences in the length of the sarcomere in the two morphs}

The mean sarcomere lengths of the LW and SW morphs were determined. The results in Fig. 5 show that the mean sarcomere lengths of LW crickets were signifi- cantly different at 12:00, 21:00 and 24:00 h $(\mathrm{P}<0.01, \mathrm{~F}=$ 85.09 , DFn $=2, \mathrm{DFd}=72$ ). Compared to controls sampled at 12:00, the mean lengths of the sarcomeres in LW flight muscles were much shorter at 21:00, just before flight, and the shortest sarcomere length occurred at 24:00, $2 \mathrm{~h}$ after lights off. Importantly, the sarcomeres of the LW morph were more contracted than those of the SW morph $(\mathrm{P}<0.01, \mathrm{~F}=126.97, \mathrm{DFn}=1, \mathrm{DFd}=72)$ (Fig. 5). Moreover, the interaction between time of day and wing morph on sarcomere length was also extremely significant $(\mathrm{P}<0.01, \mathrm{~F}=63.83, \mathrm{DFn}=2, \mathrm{DFd}=72)$. The wing morphs differ in sarcomere lengths at 21:00 and 24:00 h, which is the flight period (Fig. 5). Longitudinal sections of the flight muscles of LW and SW individuals are depicted in Fig. 3.

\section{Myofibrillar diameter}

The myofibrillar diameters of LW and SW crickets were compared and found to be much shorter in LW than in SW adults (Table 1). More importantly, in LW adults, the diameter of the myofibrils increased significantly from 12:00 to 21:00, i.e. from rest to pre-flight. However, there was no significant change in myofibrillar diameter in SW adults between 12:00 and 21:00, but there was one between 21:00 and 24:00, which is $2 \mathrm{~h}$ after lights off (Table 1). 

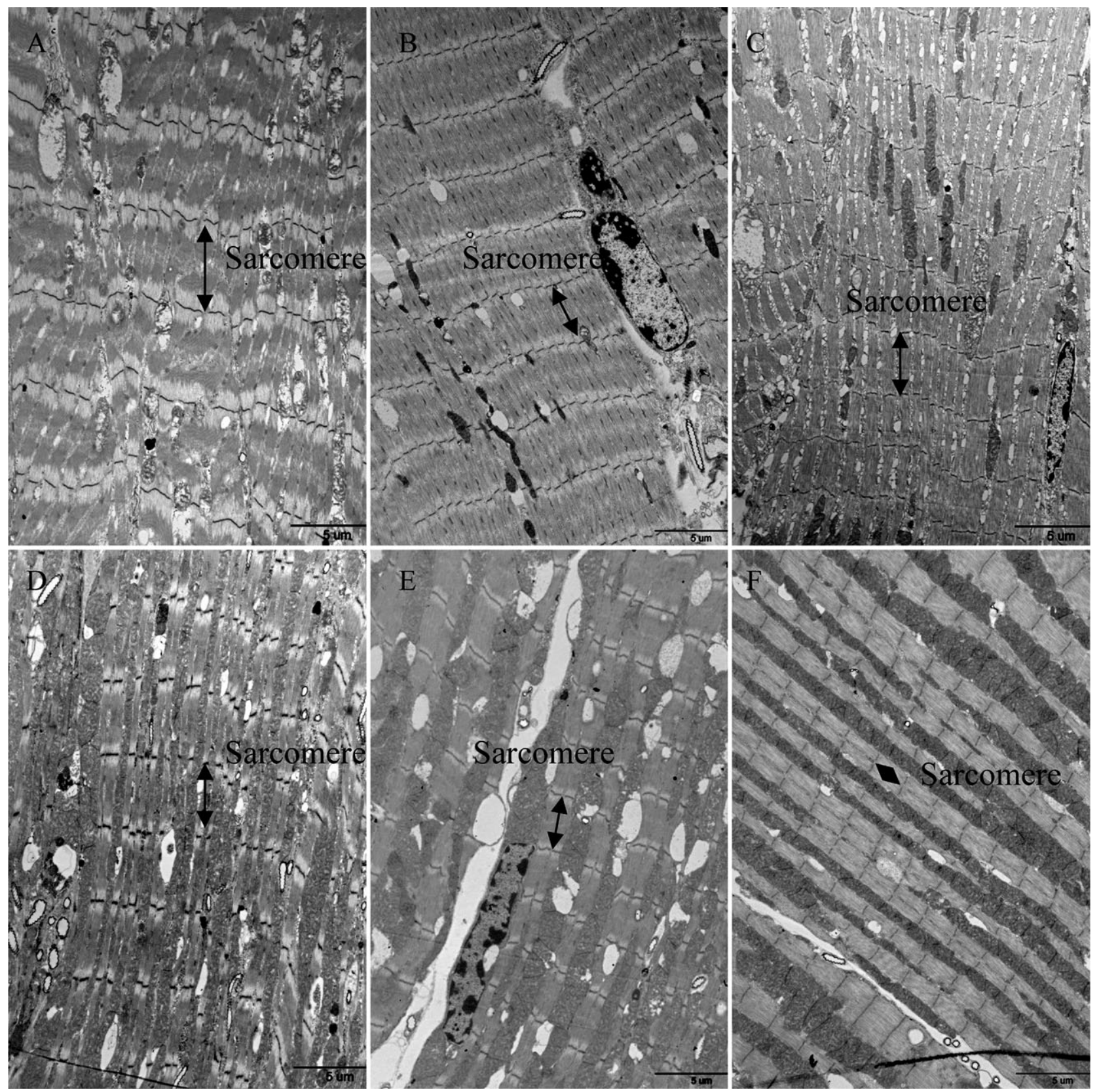

Fig. 3. Comparison of the ultrastructure of the flight muscle of SW and LW crickets with special respect to sarcomeres at different times of the day (longitudinal section, $\times 6000$ ). A-C $-\mathrm{SW}$ at different times of the day: A $-12: 00 ; \mathrm{B}-21: 00 ; \mathrm{C}-24: 00$. D-F $-\mathrm{LW}$ at different times of the day: D - 12:00; E-21:00; F - 24:00.

\section{Thick filament density}

In general, thick filaments were significantly denser in LW than in SW individuals at all three sampling times
$(\mathrm{P}<0.01, \mathrm{~F}=31.94, \mathrm{DFn}=1, \mathrm{DFd}=20)($ Fig. 6). This investigation also found that the density of thick filaments in the two wing morphs did not change significantly over

TABLE 1. Comparison of the diameter of the myofibrils in the two morphs.

\begin{tabular}{lccc}
\hline & $12: 00$ & $21: 00$ & $24: 00$ \\
\hline $\mathrm{LW}(\mathrm{n}=12)$ & $1519.205 \pm 90.16913 \mathrm{a}(\mathrm{a})$ & $2309.07 \pm 139.9631 \mathrm{a}(\mathrm{b})$ & $2996.761 \pm 227.6483 \mathrm{a}(\mathrm{bc})$ \\
$\mathrm{SW}(\mathrm{n}=12)$ & $2751.503 \pm 153.4649 \mathrm{~b}(\mathrm{a})$ & $3515.925 \pm 426.0159 \mathrm{~b}(\mathrm{ab})$ & $3600.838 \pm 222.6991 \mathrm{~b}(\mathrm{~b})$ \\
\hline
\end{tabular}

Note: The lower case letters not in brackets indicate significant differences between wing morphs at the 0.05 level. The lower case letters in brackets indicate significant differences at different times of the day at the 0.05 level (repeated measures ANOVA followed by the Bonferroni post-hoc test). There is no interaction between time of day and wing morph in myofibrillar diameter (P $>$ $0.05, \mathrm{~F}=1.19, \mathrm{DFn}=2, \mathrm{DFd}=44)$. The effect of wing morph on the myofibrillar diameter is significant $(\mathrm{P}<0.01, \mathrm{~F}=25.26, \mathrm{DFn}$ $=1, \mathrm{DFd}=44)$. The effect of time of day on the myofibrillar diameter is also significant $(\mathrm{P}<0.01, \mathrm{~F}=13.25, \mathrm{DFn}=2, \mathrm{DFd}=44)$. 

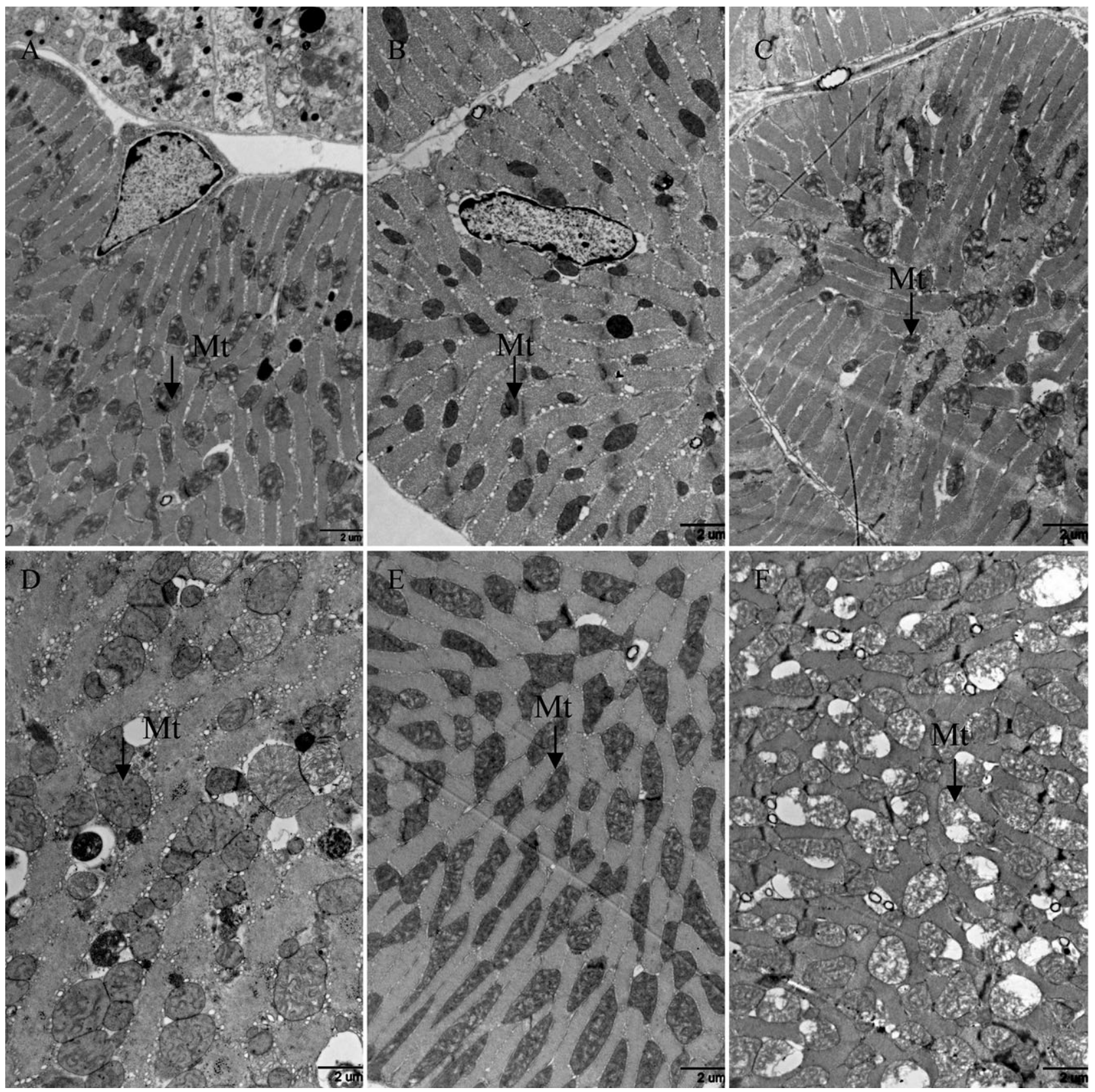

Fig. 4. Comparison of the ultrastructure of the flight muscle of SW and LW crickets with special respect to mitochondria at different times of the day (cross section, $\times 10,000$ ). A-C $-\mathrm{SW}$ at different times of the day: A $-12: 00 ; \mathrm{B}-21: 00 ; \mathrm{C}-24: 00$. D-F LW at different times of the day: D - 12:00; E - 21:00; F - 24:00.

time $(\mathrm{P}>0.05, \mathrm{~F}=2.11, \mathrm{DFn}=2, \mathrm{DFd}=20)$. There was no interaction between time of day and wing morph $(\mathrm{P}>$ $0.05, \mathrm{~F}=1.17, \mathrm{DFn}=2, \mathrm{DFd}=20$ ).

\section{Mitochondria}

The numbers of mitochondria in the flight muscles were found to be much higher in LW than SW morphs.

TABLE 2. Numbers and shapes of mitochondria in the two morphs.

\begin{tabular}{rccc}
\hline \multicolumn{1}{c}{ Morph: time } & Numbers of mitochondria (mean + S.E.) & Oval (\%) & Irregular (\%) \\
\hline LW: $12: 00$ & $29.3 \pm 2.63$ & 87.4 & 12.6 \\
$21: 00$ & $34.9 \pm 0.73$ & 6.6 & 93.4 \\
24:00 & $29.6 \pm 1.64$ & 91.2 & 8.8 \\
SW: $12: 00$ & $12.9 \pm 0.71$ & 95.3 & 4.7 \\
$21: 00$ & $16.6 \pm 1.23$ & 94.6 & 5.4 \\
24:00 & $15.4 \pm 1.44$ & 98.1 & 1.9 \\
\hline
\end{tabular}

Note: Number of mitochondria were counted in a $100 \mu \mathrm{m}^{2}$ area, in which mitochondria were either irregular or oval in shape. 


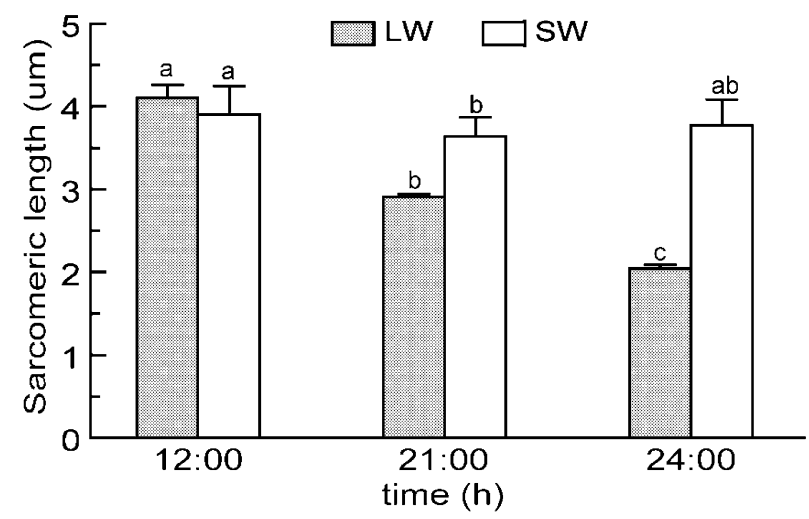

Fig. 5. Changes in the length of the sarcomere in the flight muscles of adult Gryllus firmus. Bars represent mean \pm S.E. (n $=19$ ). Bars labelled with different letters are significantly different (repeated measures ANOVA followed by Bonferroni post-hoc tests). The interaction between time of day and wing morph on sarcomere length is extremely significant $(\mathrm{P}<0.01, \mathrm{~F}$ $=63.83$, DFn $=2, \mathrm{DFd}=72)$. The effect of wing morph on sarcomere length is significant $(\mathrm{P}<0.01, \mathrm{~F}=126.97, \mathrm{DFn}=1$, $\mathrm{DFd}=72)$. The effect of daytime on the sarcomere length is also significant $(\mathrm{P}<0.01, \mathrm{~F}=85.09, \mathrm{DFn}=2, \mathrm{DFd}=72)$.

The mitochondria were irregular or oval in shape. Importantly, in the LW morph, the shape of most mitochondria changed from oval at 12:00 to irregular at 21:00, returning to oval at 24:00 (Fig. 7). Interestingly, in the SW morph, the mitochondria were always oval and clustered around the nuclei, which were unevenly distributed. In addition, in the LW morph, mitochondria were also darker in colour at 21:00, before lights off, than at other times during the day (Fig. 4). These data indicate that variations in the density, number, shape and colour of the mitochondria in the flight muscles may be important for flight in G. firmus. Cross-sections of the flight muscles of LW and SW individuals are shown in Fig. 4 and the numbers and shapes of the mitochondria in Table 2 .

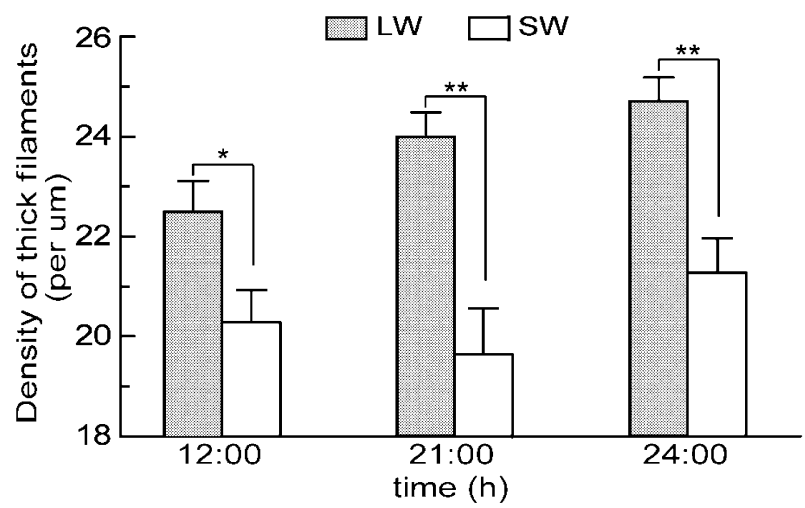

Fig. 6. The density of the thick filaments in the wing muscles of the two morphs. Bars represent mean \pm S.E. $(n=15)$. Data were analyzed using Repeated-Measures ANOVA, particular differences were determined using Bonferroni post-hoc tests. * $\mathrm{P}<0.05, * * \mathrm{P}<0.01$. There is no interaction between time of day and wing morph $(\mathrm{P}>0.05, \mathrm{~F}=1.17, \mathrm{DFn}=2, \mathrm{DFd}=20)$. The effect of wing morph on the density of thick filaments is significant $(\mathrm{P}<0.01, \mathrm{~F}=31.94, \mathrm{DFn}=1, \mathrm{DFd}=20)$. The effect of time of day on the density of thick filaments is not significant $(\mathrm{P}>0.05, \mathrm{~F}=2.11, \mathrm{DFn}=2, \mathrm{DFd}=20)$.

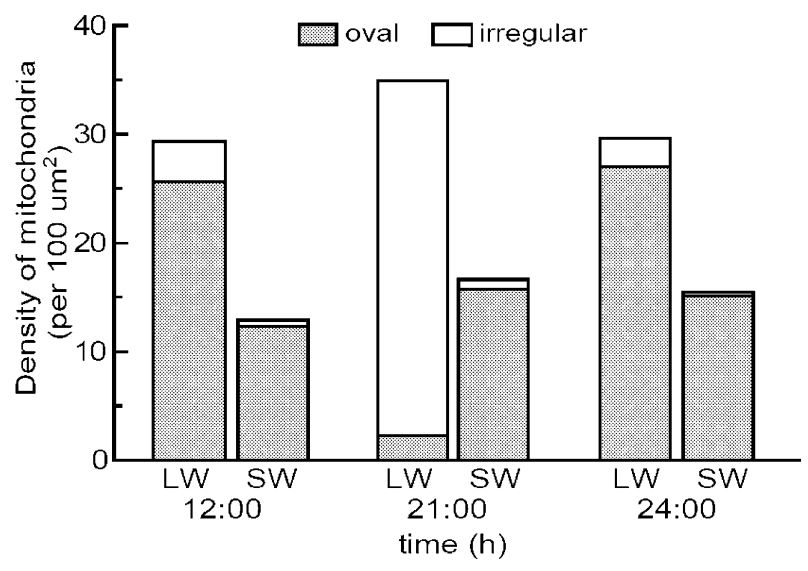

Fig. 7. Density and shape of the mitochondria in flight muscles of the two morphs. Mitochondrial density is the number of mitochondria in per $100 \mu \mathrm{m}^{2}$ of cross-sectional area. All mitochondria were either irregular or oval in shape.

\section{DISCUSSION}

\section{Sarcomeres}

The structure of insect flight muscles can be used for determining their migration status. As for muscle contraction, Pringle (1981) states that the intensity of muscle contractions is directly related to the orderliness of the arrangement of filaments and inversely related to the ratio of thick filaments to thin. Sliding filament theory states that muscle contractions are produced by the interaction of actin and myosin filaments (Mijailovich et al., 1996). The sarcomere is important in muscle contraction. Sarcomere number, not length, determines contraction speed. The more sarcomeres in the muscle, the faster it contracts (Huxley \& Niedergerke, 1954; Thuma, 2007). However, sarcomere length is also a critical indicator of flight capability because the longer the length the fewer sarcomeres in the muscle. The main role of LW crickets is dispersal by flight. Our results showed that the density of thick filaments were significantly denser in LW than in SW individuals (Fig. 6). This indicates that LW crickets are strong flyers. On the other hand, there was an interaction between time of day and wing morph on sarcomere length but not on filament density. The effect of wing morph on both sarcomere length and filament density was significant. However, time of day only significantly affected sarcomere length, not filament density (Figs 5 and 6). This indicates that wing morph plays a more important role in determining flight ability. Moreover, muscle length can be presumed to be the same in both morphs, meaning that the wing muscles of morphs with longer sarcomeres will contract more slowly.

\section{Mitochondria}

Decreases in flight performance are due to reduced ATP availability and myosin kinetics in isolated fibers, which results in a decrease in wing-beat frequency and might indicate that differences in flight directly reflect the number of mitochondria (Molloy et al., 1997; Swank et al., 2006; Miller et al., 2008). 
In G. firmus, flight is a physical process, consuming considerable amounts of energy, in addition to causing a series of changes in physiological and biochemical metabolism and morphology (Zera et al., 1997; Auerswald \& Gäde, 2002; Zhao et al., 2010). Triglyceride is the main fuel used in flight and more lipid is stored in LW than in SW individuals of G. firmus (Zera et al., 1999; Zhao \& Zera, 2002). Mitochondria, the organelles that supply the energy, inevitably undergo changes in their morphology and structure during periods of rest and flight. In different populations of cells, mitochondria can be described as being in a state of dynamic equilibrium involving changes in their number, size and structural adaptation (Smirnova et al., 2001; Padmanabhan et al., 2006). Normal mitochondria are small, rich in cristae, with dark matrixes and smooth outer membranes. When damaged, however mitochondria become larger and rounder. The matrixes become lighter in colour and cristae become shorter and smaller or even disappear (Wu, 1996). The present results reveal that cristae and part of the cavity of mitochondria (Fig. 4F) in post-flight crickets is damaged as a consequence of the considerable consumption of energy during flight. These changes in the structure of mitochondria may be explained by either of two mechanisms. First the damage to mitochondria is a result of shortages of energy, however, it is only temporary and the affected mitochondria usually recover. The damage may be caused by a number of secondary metabolites generated during cell metabolism, such as superoxide and peroxide. The symptoms can resemble those seen in the skeletal muscle of rats suffering from chronic alcoholism. In the rat skeletal muscle model of chronic alcoholic myopathy, the mitochondria swell and take on irregular shapes, the cristae disappear and the membrane partially dissolves, resulting in a decrease in the synthesis of ATP (Wang et al., 2007; Larosche et al., 2007). Secondly, the damage may be caused by mitochondrial autophagy, which is the way damaged organelles are degraded or the capacity of a cell to produce energy is enhanced, which is either an adaptation to external stress or a means of inducing cell death (Gozuacik \& Kimchi, 2007). Zhang et al. (2008) reports that hypoxia can induce mitochondrial autophagy, which prevents cells from producing excessive ROS (reactive oxygen species) and inhibits cell death. The morphological changes in the mitochondria in cricket flight muscles may be a result of mitochondrial autophagy induced by hypoxia resulting from strenuous exercise.

\section{Fuels for flight muscles}

Laboratory studies have revealed that during flight they utilize glycogen and lipids as sources of energy. Glycogen stores are mobilized to produce trehalose for shortterm flight, but lipids are the principal source of energy for long-term flight (Cockbain, 1961). Furthermore, energy for flight comes primarily from either the metabolism of lipids or or glucose in which adipokinetic hormone $(\mathrm{AKH})$ has a very important role. It triggers the release of octopamine from octopamine-releasing neurons, such as the DUM neurons (Birkenbeil, 1971). Octopamine in turn activates catabolic enzymes, such as lipases and phosphorylases (Fassold et al., 2010). Carbohydrates, especially in the initial stages of flight, are the key fuel in some species of Orthoptera, such as $P$. sinuate (Lorenz \& Gäde, 2009). Previous results also show that the increases in trehalose and glycogen that occur before flight are important sources of fuel in Gryllus firmus, while triglyceride is mainly utilized during long-term flight (Zhang et al., 2011).

\section{Implications for the regulation of juvenile hormone}

Previous studies have shown that a hormone is involved in the development and degradation of the flight muscles and that in vivo $\mathrm{JH}$ and ecdysone control thoracic muscles (Shiga et al., 2002; Rose, 2004; Socha \& Sula, 2006; Oliver et al., 2007; Ghoneim et al., 2008). Zhao \& Zera (2004a) report a direct correlation between JH levels and flight activity in G. firmus. Thus, the changes that we observed in flight muscle tissue must be accompanied by changes in the titre of $\mathrm{JH}$, however the means by which $\mathrm{JH}$ causes the changes in sarcomere and myofilaments, and induces large numbers of mitochondria to supply energy remain unresolved. Whether these changes occur as soon as exogenous juvenile hormone is expressed and disappear when the titre of this hormone decreases are appropriate subjects for a future study.

ACKNOWLEDGEMENTS. This work was funded by the National Science Fund of China (Grant No. 30771415). We thank A.J. Zera (School of Biological Sciences, University of Nebraska) for supplying us with crickets.

\section{REFERENCES}

Auerswald L. \& GÄDE G. 2002: Physiological and biochemical aspects of flight metabolism in cocoon-enclosed adults of the fruit beetle, Pachnoda sinuata. J. Insect Physiol. 48: 239-248.

BIRKENBEIL H. 1971: Untersuchungen zur Wirkung von Neurohormon D und von anderen aktiven Substanzen auf das Zentralnervensystem der Schabe Periplaneta americana (L.). Zool. J. Physiol. 58: 493-525.

Biserova N.M. \& Pfluger H.J. 2004: The ultrastructure of locust pleuroaxillary "steering" muscles in comparison to other skeletal muscles. Zoology 107: 229-242.

Chudakova I.V. \& Bocharova-Messner O.M. 1968: Endocrine regulation of the condition of the wing musculature in the imago of the house cricket (Acheta domestica L.). Dokl. Akad. Nauk SSSR 179: 489-492.

CockBAIN A.J. 1961: Fuel utilization and duration of tethered flight in Aphis fabae Scop. J. Exp. Biol. 38: 163-174.

DAVIES I. 1974: The effect of age and diet on the ultrastructure of hymenopteran flight muscle. Exp. Gerontol. 9: 215-216.

Dickinson M.H. \& TU M.S. 1997: The function of dipteran flight muscle - turning axis and gearbox of the wing base (Insecta, Diptera). Compar. Biochem. Physiol. (A) 116: 223-238.

Dingle H. 1996: Migration: The Biology of Life on the Move. Oxford University Press, New York, 474 pp.

Fassold K., El-Damanhouri H.I.H. \& Lorenz M.W. 2010: Agedependent cyclic locomotor activity in the cricket, Gryllus bimaculatus, and the effect of adipokinetic hormone on locomotion and excitability. J. Comp. Physiol. (A) 196: 271-283.

GHoneim K.S., BaKr R.F., TANANi M.A., AL Dali A.G. \& BREAM A.S. 2008: An ultrastructural study on the desert locust (Schistocerca gregaria) as affected by Tebufenozide (RH-5992). Int. J. Agr. Biol. 10: 479-480. 
GozuaciK D. \& Kiмchi A. 2007: Autophagy and cell death Curr. Top. Dev. Biol. 78: 217-245.

Herold R.C. 1965: Development and ultrastructural changes of sarcosomes during honey bee flight muscle development. Dev. Biol. 12: 269-286.

Huxley A.F. \& Niedergerke R. 1954: Structural changes in muscle during contraction. Nature 173: 971-973.

Larosche I., Letteron P., Fromenty B., Bbey-Toby A., Vadrot N., Feldmann G., Van Remmen H., Richardson A., Pessayre D. \& MANSOURI A. 2007: Overexpression of manganese superoxide dismutase triggers mitochondral damage after chronic alcohol intoxication in mouse liver. J. Hepatol. 46 : 272

LORENZ M.W. \&. GADE G. 2009: Hormonal regulation of energy metabolism in insects as a driving force for performance. Integr. Comp. Biol. 49: 380-392.

Mentel T., Duch C., Stypa H., Muller U. \& Wegener G. 2003: Central modulatory neurons control fuel selection in flight muscle of migratory locust. J. Neurosci. 23: 1109-1113.

Mijailovich S.M., Fredberg J.J. \& Butler J.P. 1996: On the theory of muscle contraction: filament extensibility and the development of isometric force and stiffness. Biophys. J. 71: 1475-1484.

Miller M.S., Lekkas P., Braddork J.M., Farman G.P., Ballif B.A., Irving T.C., Maughan D.W. \& Vigoreaux J.O. 2008: Aging enhances indirect flight muscle fiber performance yet decreases flight ability in Drosophila. Biophys. J. 95: 2391-2401.

Mizisin A.P. \& REady N.E. 1986: Growth and development of flight muscle in the locust (Schistocerca nitens). J. Exp. Zool. 237: $45-55$.

Molloy J.E., Kyrtatas V., Sparrow J.C. \& White D.C. 1987: Kinetics of flight muscles from insects with different wingbeat frequencies. Nature 328: 449-451.

Novicki A. 1989: Control of growth and ultrastructural maturation of a cricket flight muscle. J. Exp. Zool. 250: 263-272.

Oliver R.H., Albury A.N.J. \& Mousseau T.A. 2007: Programmed cell death in flight muscle histolysis of the house cricket. Insect Physiol. 53: 30-39.

Padmanabhan R., TariQ N.M.A.S. \& ShaWullah M. 2006: Mitochondrial dysmorphology in the neuroepithelium of rat embryos following a single dose of maternal hyperthermia during gestation. Exp. Brain Res. 173: 298-308.

PRINGLE J.W.S. 1981: The evolution of fibrillar muscle in insect. J. Exp. Biol. 94: 1-14.

REEDY M.K. 1968: Ultrastructure of insect flight muscle: I. Screw sense and structural grouping in the rigor cross-bridge lattice. Mol. Biol. 31: 155-162.

ReEdy M.C. \& BeAll C. 1993: Ultrastructure of developing flight muscle in Drosophila. I and II. Dev. Biol. 160: 443-479.

Rose U. 2004: Morphological and functional maturation of a skeletal muscle regulated by juvenile hormone. J. Exp. Biol. 207: 483-495.

RUPPERT E.E., Fox R.S. \& BARNS R.D. 2003: Invertebrate Zoology: A Functional Evolutionary Approach. 7th ed. Brooks Cole Thomson, Belmont, CA, 963 pp.

SACKTOR B. 1970: Regulation of intermediary metabolism with special reference to the control mechanisms in insect flight muscle. Adv. Insect Physiol. 7: 267-347.

Shiga S., Yasuyama K., Okamura N. \& Yamaguchi T. 2002: Neural- and endocrine control of flight muscle degeneration in the adult cricket, Gryllus bimaculatus. J. Insect Physiol. 48: $15-24$.

Smirnova E., Griparic L., Shurland D.L. \& van der Bliek A.M. 2001: Dynamin-related protein Drp1 is required for mitochondrial division in mammalian cells. Mol. Biol. Cell 12: 2245-2256.
Socha R. \& Sula J. 2006: Flight muscles polymorphism in a flightless bug, Pyrrhocoris apterus (L.): Developmental pattern, biochemical profile and endocrine control. Insect Physiol. 52: 231-239.

Srihari T., Gutmann E. \& Novak V.J.A. 1975: Effect of ecdysterone and juvenoid on the developmental involution of flight muscles in Acheta domestica. J. Insect Physiol. 21: 1-8.

Swank D.M., Vishnudas V.K. \& Maughan D.W. 2006: An exceptionally fast actomyosin reaction powers insect flight muscle. PNAS 103: 17543-17547.

Thuma J.B., Harness P.I., Koehnle T.J., Morris L.G. \& Hooper S.L. 2007: Muscle anatomy is a primary determinant of muscle relaxation dynamics in the lobster (Panulirus interruptus) stomatogastric system. J. Comp. Physiol. (A) 193: 1101-1113.

Usherwood P.N.R. (ed.) 1975: Insect Muscle. Academic Press, London, $621 \mathrm{pp}$.

Veazy J.N., Kay C.A.R., Walker T.J. \& Whitcomb W.H. 1976: Seasonal abundance, sex ratio, and macroptery of field crickets in northern Florida. Ann. Entomol. Soc. Am. 69: 374-380.

Wang J.F., Chu H.Y., Zhao H., Cheng X., Liu Y., Jin W., Zhao J., LIU B., Ding Y. \& MA H. 2007: Nitricoxide synthaseinduced oxidative stress in prolonged alcoholic myopathies of rats. Mol. Cell. Biochem. 304: 135-142.

Wu Z.B. 1996: Damage of cell and tissue. In Wu Z.B.: Pathology. Vol. 4. People's Medical Press, Beijing.

Zera A.J. \& Cisper G. 2001: Genetic and diurnal variation in the juvenile hormone titer in a wing-polymorphic cricket: Implications for the evolution of life histories and dispersal. Physiol. Biochem. Zool. 74: 293-306.

Zera A.J. \& Denno R.F. 1997: Physiology and ecology of dispersal polymorphism in insects. Annu. Rev. Entomol. 42: 207-231.

Zera A.J. \& Harshman L. 2001: Physiology of life history trade-offs in animals. Annu. Rev. Ecol. Evol. Syst. 32: 95-126.

Zera A.J., Sall J. \& Grudzinski K. 1997: Flight-muscle polymorphism in the cricket Gryllus frmus: muscle characteristics and their influence on the evolution of flightlessness. Physiol. Zool. 70: 519-529.

Zera A.J., Sall J. \& Otтo K. 1999: Biochemical aspects of flight and flightlessness in Gryllus: flight fuels, enzyme activities and electrophoretic profiles of flight muscles from flight-capable and flightless morphs. Insect Physiol. 45: 275-285.

Zhang H., Bosch-Marce M. \& Shimoda L.A. 2008: Mitochondrial autophagy is a HIF-1-dependent adaptive metabolic response to hypoxia. Biol. Chem. 283: 10892-10903.

Zhang B.C., Jiang C.J., Zhang Q.W. \& Zhao Z.W. 2011: Variations in fuel use in the flight muscles of wing-dimorphic Gryllus firmus and implications for morph-specific dispersal. Enviorn. Entomol. 40: 1566-1571.

Zhao Z.W. \& Zera A.J. 2002: Differential lipid biosynthesis underlies a tradeoff between reproduction and flight capability in a wing-polymorphic cricket. PNAS 99: 16829-16834.

ZhaO Z.W. \& ZeRA A.J. 2004a: The hemolymph JH titer exhibits a large-amplitude, morph-dependent, diurnal cycle in the wing-polymorphic cricket, Gryllus firmus. J. Insect Physiol. 50: 93-102.

ZhaO Z.W. \& ZeRA A.J. 2004b: A morph-specific daily cycle in the rate of $\mathrm{JH}$ biosynthesis underlies a morph-specific daily cycle in the hemolymph $\mathrm{JH}$ titer in a wing-polymorphic cricket. J. Insect Physiol. 50: 965-973.

Zhaо Q.L., Zhu D.H. \& ZeNG Y. 2010: Physiological trade-offs between flight muscle and reproductive development in the wing-dimorphic cricket Velarifictorus ornatus. Entomol. Exp. Appl. 135: 288-294.

Received May 30, 2011; revised and accepted May 21, 2012 